\title{
REDES INTERORGANIZACIONAIS: A Realidade dos Pequenos Supermercadistas da Região Metropolitana de Belo Horizonte-MG ${ }^{1}$
}

\section{BUSINESS NETWORKS: The Reality of Small Supermarkets in the Metropolitan Region of Belo Horizonte-MG}

\section{REDES DE NEGOCIOS: La Realidad de Los Pequeños Supermercados en la Región Metropolitana de Belo Horizonte-MG}

Hudson Soares Moreira, Mestre em Administração. Endereço Profissional: Universidade Federal de Minas Gerais (UFMG), Campus Pampulha. Av. Pres, Antônio Carlos, 6627, Pampulha, Belo Horizonte, MG - Brasil, CEP 31270-901. Telefone: (031) 9 8478.5353. Homepage: http://www.face.ufmg.br/departamentos.htm. E-mail:

hudsonsmoreira@gmail.com.

Wendel Alex Castro Silva, Doutor em Administração. Professor do Programa de Mestrado do Centro Universitário Unihorizontes. Endereço Profissional: R. Alvarenga Peixoto, 1270, Santo Agostinho, Belo Horizonte, MG - Brasil, CEP 30180-121. Telefone: (031) 33352248.

Homepage: http://mestrado.unihorizontes.br/. E-mail:

wendel.silva@mestrado.unihorizontes.br

Márcia Athayde Moreira, Doutora em Controladoria e Contabilidade. Professora do Programa de Mestrado e Doutorado da Universidade da Amazônia - Unama. Endereço Profissional: Av. Alcindo Cacela, 287, Umarizal, Belém, PA - Brasil, CEP:

66.065-205. Telefone: (091) 4008 3018. Homepage:

http://www.unama.br/conteudo/mestrados-doutorados. E-mail:

athayde.marcia@gmail.com

\section{RESUMO}

Parte-se da premissa de que, nos últimos anos, o setor supermercadista tornou-se altamente competitivo, o que estimulou os pequenos varejos supermercadistas a procurar novas estratégias, tais como a organização por meio de redes, em busca da sustentabilidade do negócio. Nesse contexto, essa pesquisa teve como objetivo investigar como o pequeno varejo supermercadista da região metropolitana de Belo Horizonte se organiza em redes. Para tanto foi realizada uma pesquisa de cunho exploratória, por meio de pesquisa bibliográfica, análise documental de documentos da Associação Mineira de Supermercados (AMIS) e entrevistas com os gestores das sete redes varejistas supermercadistas organizadas na região metropolitana. Todas as redes são horizontais, setoriais, sendo a maioria formalizada, somando 162 supermercados participantes. As redes não possuem atividades entre si (interredes) apenas atividades em relação aos próprios associados (intrarrede), tais como estrutura de apoio às compras e distribuição de mercadorias. Negociam em nome dos supermercadistas e obtêm

\footnotetext{
${ }^{1}$ Artigo submetido em 18/12/2014, revisado em 12/03/2017, aceito em 13/06/2017 e divulgado em 15/12/2017 pelo Editor João Carlos Hipólito Bernardes do Nascimento, após double blind review.
}

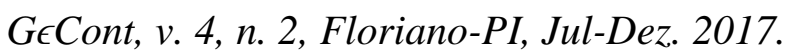


descontos e dilatação de prazos para pagamento, entre outros benefícios oferecidos, tais como treinamentos para empregados e proprietários. Conclui-se que as redes estão se profissionalizado, mas com grandes diferenças entre os quesitos pesquisados, seja na forma de interação com seus associados, seja na forma de negociação ou mesmo na estrutura física e na estrutura de gestão.

Palavras-chave: redes empresariais; pequenas empresas; varejo supermercadista; profissionalização.

\begin{abstract}
In recent years the supermarket industry has become highly competitive, which encouraged small markets retailers to seek for new strategies, such as organizing through networks in order to achieve business sustainability. In this context, this research aimed to investigate how the small grocery stores in the metropolitan region of Belo Horizonte are organized in networks. This study is methodologically classified as an exploratory research, with documentary analysis of papers from the Association of Minas Gerais Supermarkets (AMGS) and data collected also from interviews with managers from seven organized retailers markets in the metropolitan region. The results indicate that all networks are horizontal, sectored, and most like formalized, in a total of 162 participants markets. The networks do not have activities together; however they are somehow associated, such as supporting structure for procurement and distribution of products. The network negotiate on behalf of the grocery stores and get discounts and extension of payment terms, also they are other benefits, such as training for employees and managers. In conclusion, those networks are in processing of professionalization, but with large differences between the questions surveyed, whether in the form of interaction with their members, either as trading or even the physical structure and management organization.
\end{abstract}

Keywords: business networks; small businesses; retail supermarket; professionalization.

\title{
RESUMEN
}

En los últimos años, la industria de los supermercados se ha vuelto altamente competitiva, lo que alentó a los pequeños comerciantes minoristas a buscar nuevas estrategias, como la organización a través de redes para lograr la sostenibilidad del negocio. En este contexto, esta investigación tuvo como objetivo investigar cómo las pequeñas tiendas de abarrotes en la región metropolitana de Belo Horizonte se organizan en redes. Este estudio se clasifica metodológicamente como una investigación exploratoria, con análisis documental de documentos de la Asociación de Supermercados de Minas Gerais (ASMG) y datos recopilados también de entrevistas con gerentes de siete mercados organizados de minoristas en la región metropolitana. Los resultados indican que todas las redes son horizontales, sectoriales y, en general, formalizadas, en un total de 162 mercados participantes. Las redes no tienen actividades juntas; sin embargo, están asociados de alguna manera, como la estructura de apoyo para la adquisición y distribución de productos. La red negocia en nombre de las tiendas de comestibles y obtiene descuentos y extensiones de los términos de pago, además de otros beneficios, como la capacitación de empleados y gerentes. En conclusión, esas redes están en proceso de profesionalización, pero con grandes diferencias entre las preguntas encuestadas, ya sea en forma de interacción con sus miembros, ya sea como negociación o incluso la estructura física y la organización de gestión.

Palabras clave: redes empresariales; pequeñas empresas; supermercado minorista; profesionalización. 


\section{INTRODUÇÃO}

$\mathrm{P}$ ercebe-se que nos últimos anos houve um aumento significativo no consumo, devido ao aumento do poder aquisitivo dos consumidores brasileiros. Paralelamente o setor supermercadista tornou-se altamente competitivo e este fato, a competitividade, estimulou investimentos por parte de empresários, assim como incentivou os pequenos varejos supermercadistas a procurar novas estratégias, tais como a organização por meio de redes, em busca da sustentabilidade do negócio.

Nesse sentido, Amato Neto (2000) destaca que as empresas vêm sofrendo forte pressão para responder rapidamente ao mercado. A preocupação das empresas em aprimorar sua capacidade tecnológica e gerencial, ganhar flexibilidade, manter o acesso ao mercado e estar em sintonia com as mudanças internacionais caracteriza o ambiente atual, e diferentemente do passado, quando as estratégias gerenciais estavam focadas em nível da empresa, hoje as empresas já não podem agir isoladamente. Assim, notadamente para as pequenas empresas, participar de uma rede possibilita a troca de experiências tendo em vista o fortalecimento, o aumento do conhecimento dos gestores e consequentemente aumentar as possibilidades de melhores resultados.

Amato Neto (2000) menciona ainda que, historicamente, as pequenas empresas têm desempenhado um papel socioeconômico importante, tanto do âmbito da geração de emprego e de renda, quanto no âmbito de seu potencial de inovação incremental. Também constata que nem todas as pequenas empresas estão em um estágio de desenvolvimento que possam apresentar condições de modernizar-se o suficiente para competir ou, simplesmente, sobreviver no ambiente competitivo. Segundo entendimento de Pereira (2008), a participação na rede permite ao empresário adquirir habilidades e conhecimentos valiosos para a melhoria da empresa. Entende-se, portanto, que aumentando a experiência de gestão é possível transformar essa experiência em vantagem competitiva.

Nesse sentido, a troca de informações constitui uma das principais vantagens de redes empresarias. Na visão de Boehe e Silva (2003), as redes não são somente uma estratégia para as pequenas empresas enfrentarem as maiores, o que dificilmente poderia ser alcançado individualmente, mas também um elemento imprescindível para a sobrevivência. Já na visão de Ferreira et al. (2008, p. 3), as redes são apontadas como alternativa diante de vários dos problemas enfrentados pelas organizações "[...] como a grande concorrência, a competição e a necessidade de aquisição e aplicação de novos conhecimentos, representando uma resposta em torno de questões de competitividade, estratégia empresarial e estruturação organizacional".

Ainda de acordo com Ferreira et al. (2008), a constituição de redes de negócios tem representado um diferencial positivo para os pequenos supermercadistas, com impacto direto em sua performance operacional, econômica e financeira, isso porque os pequenos empresários do setor de supermercados levam uma grande vantagem, como por exemplo, o conhecimento dos hábitos de seus clientes. No entanto há desvantagens, tais como menor capital de giro para trabalhar, dificuldade de acesso a linhas de crédito, menor poder de negociação na hora da compra, dificuldade de oferecer treinamento ao pessoal, entre outros fatores negativos (FERREIRA et al., 2008), fazendo com que a associação a redes interempresariais seja uma alternativa viável para a sustentabilidade do pequeno negócio.

Diante do contexto levantado e considerando a importância da formação de redes de pequenas empresas, a questão que motiva essa pesquisa é: de que forma o pequeno varejo supermercadista da região metropolitana de Belo Horizonte se organiza em redes? Nesse sentido o objetivo dessa pesquisa consiste em identificar como o pequeno varejo supermercadista da região metropolitana de Belo Horizonte se organiza em redes, ou seja, analisar as formas de atuação e interação intra e inter-redes; identificar a forma de negociação 
das redes e as vantagens e desvantagens de ser um associado e destacar as similaridades e diferenças entre as estruturas de gestão utilizadas pelas redes.

Essa pesquisa se justifica por fomentar a discussão sobre como os pequenos varejos supermercadistas tem se organizado em redes na perspectiva de superar as dificuldades enfrentadas pelos pequenos frente aos grandes. A formação de redes surge como uma alternativa para superação das dificuldades enfrentadas, sendo de grande interesse econômico para a sustentabilidade do negócio, do setor, entre outras perspectivas, como a geração de renda e empregos locais. Dessa forma, essa pesquisa é importante para empresários do ramo supermercadista podendo gerar informações úteis e importantes para realização de ações no sentido de fortalecimento desses pequenos empreendedores. Também é importante para pesquisadores e estudantes, pois conhecendo as formas de atuação destas redes, podem promover um debate sobre o desempenho, a sustentabilidade, as ações empresariais e seus reflexos na sociedade.

A pesquisa está estruturada em cinco tópicos. Sendo o primeiro a Introdução, contendo: contexto, questão de pesquisa, objetivos e a justificativa. $O$ segundo tópico se dedica à revisão de literatura. $\mathrm{O}$ terceiro tópico descreve a metodologia utilizada para a realização da análise empírica, a qual tem seus resultados apresentados no quarto tópico. $\mathrm{O}$ quinto e último tópico apresenta as considerações finais.

\section{REFERENCIAL TEÓRICO}

\section{$2.1 \quad$ CONCEITOS}

Na visão de Ferreira et al. (2008, p. 3), "uma rede é uma organização intermediária entre a empresa e o mercado pela necessidade de coordenação das atividades econômicas, representando um arranjo híbrido, contendo elementos de mercado e de hierarquia". Os autores defendem que as organizações são redes sociais, "[...] num ambiente onde um conjunto de empresas se interliga e mantêm constante interação, promovendo relacionamentos entre os atores sociais em espaços internos e externos" (FERREIRA et al., 2008, p. 3).

Nesse contexto apresentado pelos autores, as redes organizacionais "[...] representam uma estrutura celular, não rigorosa e composta de atividades de valor agregado, de empresas que não podem assegurar individualmente as condições de sobrevivência e desenvolvimento requeridas pelo ambiente complexo e dinâmico" (FERREIRA et al., 2008, p. 3).

A palavra rede traduz a ideia de entrelaçamento, imbricamento e malha de relações capazes de capturar informações essenciais em dois níveis: a conectividade, entendida como a capacidade estrutural de facilitar a comunicação entre seus componentes, e a coerência, entendida como a existência de objetivos e interesses compartilhados entre os componentes da rede (CASTELLS, 2000).

Amato Neto (2000) considera que redes são um conjunto ou uma série de células interconectadas por relações bem definas, podendo ser também consideradas como formas especiais de alianças estratégicas entre empresas. Segundo Amato Neto (2000) as competências e atribuições de uma rede de empresas estão basicamente ligadas aos processos de coordenação que uma coalizão interfirmas pode empregar.

Nesse sentido, de acordo com Ballestero et al. (2004), uma rede é composta por um conjunto ou grupo de organizações interconectadas por relação bem definidas, sejam elas de um setor ou situadas ao longo de uma cadeia produtiva, esta pesquisa foca o setor varejista supermercadista. Partindo desses conceitos iniciais, serão abordados alguns pontos importantes para o entendimento sobre a organização e a importância das redes dentro do setor alvo desta pesquisa e também para a sociedade como um todo. 


\subsection{ANTECEDENTES}

Toda análise sobre a história da humanidade tem revelado que justamente nos momentos de crise e de incertezas é que se criam os elementos necessários para que transformações estruturais ocorram nos mais variados campos da ciência, da tecnologia, do comportamento e da sociedade. Nesse sentido, acompanhando a evolução dos paradigmas científicos, a tecnologia e a organização produtiva também passaram por várias transformações (AMATO NETO, 2000).

Caracterizando a evolução tecnológica e seus impactos nas formas de gestão, Amato Neto (2000) traça uma linha do tempo: no fim da segunda metade do século XIX surgem o motor de combustão interna e o motor elétrico, durante os anos 30 do século XX surgem o radar, os aviões a jato, além de outras inovações significativas na indústria. Mais recentemente, nas décadas de 70 e 80 outras inovações de caráter revolucionário impactam toda a estrutura produtiva da indústria mundial.

Dessa forma, o progresso técnico constituiu a melhora das variáveis tecnológicas e se expressa por meio de uma série de inovações secundárias de produtos e processos e nesse contexto surgiu a ideia de agrupamento (clustering) de inovações e das transformações ocorridas na base técnica do sistema econômico. A partir da década de 80 a indústria estrangeira estabelecida no Brasil oportunizou a implantação de pequenas empresas especializadas no atendimento de determinados bens e serviços que originalmente não interessavam ou não tinham como ser realizados pelas empresas transnacionais estabelecidas aqui, originalmente trabalhando com processos de baixa tecnologia e mão de obra intensiva. Amato Neto (2000) destaca que atualmente (já na primeira década do século XXI) a criação de incubadoras e parques tecnológicos mudou o papel da pequena empresa no cenário nacional.

Assim amadureceram os arranjos intra e interempresas, com a formação e o desenvolvimento de redes, notadamente aquelas envolvendo pequenas organizações. As empresas ao atuarem em redes, podem se complementar tanto nos aspectos técnicos (meios produtivos), como nos aspectos mercadológicos (redes de distribuição). Ao constituir uma rede de empresas, esperam agregar conhecimento e obter vantagens competitivas.

\subsection{TIPOLOGIAS DE REDES DE EMPRESAS}

De acordo com Pereira (2008) modelo de associação formado pelas redes é uma estratégia em franca expansão, principalmente no segmento das pequenas empresas em função da competitividade do mercado globalizado e das altas tecnologias de informação e comunicação.

Essas redes permitem aos associados almejarem melhores condições de negociação junto a fornecedores e instituições financeiras, buscando maior competitividade. De acordo com Amato Neto (2000) e Ferreira et al. (2008) as redes se classificam em Sociais ou Informais, Burocráticas ou Formais e Proprietárias, sendo que essas últimas se subdividem em verticais ou horizontais.

Redes verticais de cooperação são encontradas normalmente nos casos em que as relações de cooperação ocorrem entre uma empresa e os componentes dos diferentes elos ao longo de uma cadeia produtiva, como por exemplo, as relações de fornecimento no complexo automobilístico. Enquanto que a relação entre empresas que produzem e/ou oferecem produtos similares, pertencentes a um mesmo setor ou ramo de atuação, isto é, entre uma empresa e seus próprios concorrentes, são denominadas as redes horizontais de cooperação (AMATO NETO, 2000). 
Segundo Amato Neto (2000), as redes horizontais de cooperação são implantadas quase sempre quando empresas de forma isolada apresentam dificuldades em adquirir ou partilhar recursos e atender o mercado que atuam.

Destaca-se que as redes objeto de pesquisa nesse estudo são caracterizadas como redes formais burocráticas e proprietárias do tipo horizontal.

\subsection{MOTIVAÇÕES PARA O ESTABELECIMENTO DE REDES}

Redes surgem das muitas dificuldades e limitações competitivas de ações isoladas de empresários. Nesse sentido, a base conceitual das redes é "[...] juntar esforços em funções que necessitem de uma escala maior e maior necessidade inovativa para sua viabilidade competitiva" (CASSAROTTO FILHO; PIRES, 1998, p.39).

A formação das redes de cooperação interempresarial pode ser motivada por diversos fatores, tais como os discutidos por Oliver (1990) e estruturados por Amato Neto (2005), apresentados no Quadro 1:

\section{Quadro 1: Fatores de motivação para formação de redes}

\begin{tabular}{|c|c|}
\hline Fator de Motivação & Exemplos Práticos \\
\hline $\begin{array}{l}\text { Imposição legal ou de uma instância } \\
\text { superior }\end{array}$ & $\begin{array}{l}\text { Caso de certas linhas de financiamento, às quais é permitido acesso } \\
\text { somente a consórcios entre empresas e instituições de pesquisa. }\end{array}$ \\
\hline Busca por controle & $\begin{array}{l}\text { Quando uma organização procura exercer controle sobre outra ou } \\
\text { sobre seus recursos de outra organização. }\end{array}$ \\
\hline Reciprocidade & $\begin{array}{c}\text { Quando relações são estabelecidas por organizações que } \\
\text { compartilham objetos comuns, iniciando relações de cooperação e } \\
\text { coordenação. }\end{array}$ \\
\hline Necessidade de maior eficiência interna & $\begin{array}{l}\text { Quando uma organização preocupada em melhorar sua própria } \\
\text { eficiência, busca estabelecer relações com outras empresas para } \\
\text { reduzir seus custos de transação. }\end{array}$ \\
\hline Busca por estabilidade & $\begin{array}{l}\text { Devido às incertezas do ambiente competitivo, buscam o } \\
\text { estabelecimento de relações para diminuir a sua vulnerabilidade. }\end{array}$ \\
\hline Procura de legitimidade & $\begin{array}{c}\text { Quando uma organização busca melhorar tanto sua reputação e } \\
\text { imagem quanto sua visibilidade e prestígio por meio do } \\
\text { estabelecimento de relações com organizações aceitas e respeitadas } \\
\text { em seu meio. }\end{array}$ \\
\hline
\end{tabular}

Fonte: Elaborado pelos autores, conforme Amato Neto (2005, p. 55)

Entre os fatores de motivação que devem influenciar os pequenos varejos supermercadistas a se organizar em redes destacam-se a reciprocidade em compartilhar os objetivos comuns cooperando para a tomada de decisões frente às adversidades, necessidade de maior eficiência interna para diminuir custos e obter melhores lucros e a busca por estabilidade visando diminuir a vulnerabilidade diante das grandes redes supermercadistas.

Para Amato Neto (2000) a cooperação interempresarial pode facilitar a satisfação de uma série de necessidades das empresas, que isoladamente dificilmente poderiam ser satisfeitas. Entre essas necessidades destacam-se: aproveitar competências e utilizar know how das outras empresas; dividir riscos e custos de explorar novas oportunidades; exercer uma pressão maior no mercado, aumentando a força competitiva, possibilitando benefícios ao cliente; e, aumentar o poder de compra.

A cooperação entre empresas de uma rede pode propiciar a solução para uma série de necessidades, destacando a combinação da competência e o know how de gestores de outras empresas; compartilhando o desenvolvimento e conhecimento adquirido; dividindo os custos

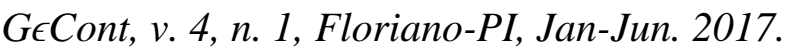


na exploração de novas oportunidades, partilhando riscos, realizando experiências em conjunto; exercendo maior pressão sobre o mercado; compartilhando recursos; e, fortalecendo o poder de compra (AMATO NETO, 2000).

\subsection{FLUXO DE RECURSOS ENTRE REDES INTEREMPRESARIAIS}

Amato Neto (2005) descreve fatores de influência no estabelecimento do fluxo de recursos em redes interempresariais, agrupados em dois blocos: os recursos de redes que a organização possui e a competência administrativa para trabalhar em cooperação.

Em condições de reciprocidade, uma organização entra em uma rede se possuir algum tipo de recurso, tais como informação, serviço ou produto, que seja de interesse para os demais participantes, "[...] recursos de rede são, para organizações, o equivalente ao capital social para indivíduos" (AMATO NETO, 2005, p. 60). No âmbito do indivíduo, seus relacionamentos são ativos valiosos e se constituem em seu capital social, pois podem lhe abrir novas alternativas de negócios e conseguir-lhe novas colocações. Da mesma forma, "[...] as organizações possuem relações com outras, que lhes possibilitam novos contatos, negócios e oportunidades" (AMATO NETO, 2005, p. 60).

Sabe-se que para participar de uma rede é necessário ter determinadas competências organizacionais. O desenvolvimento de competências administrativas por parte de cada organização envolvida é imprescindível, e as organizações devem desenvolver a gestão do conhecimento interno, mantendo-se em constante atividade de cooperação, adquirindo e armazenando conhecimento para disseminá-lo para quem for fazer uso dele (AMATO NETO, 2005).

Outro importante facilitador do fluxo de recursos dentro de uma rede é a confiança. Uma organização entra em uma rede esperando obter vantagens para si, e em condições de reciprocidade essa organização deve procurar aumentar o potencial para a troca de informações, buscando a resolução conjunta de problemas em uma base de confiança dentro da rede (AMATO NETO, 2005).

Por outro lado, Amato Neto (2000) destaca um fator que poderia ser considerado uma séria barreira para o desenvolvimento e o fluxo de recursos em redes de cooperação. Este fator refere-se à cultura empresarial predominante que pode se caracterizar por um comportamento empresarial individualista, de perspectivas de curto prazo e de lucros imediatos, tendo grande desconfiança com relação ao estabelecimento de alianças estratégicas, parcerias ou de quaisquer tipos de associações interempresariais.

\subsection{FATORES DE SUSTENTABILIDADE}

Amato Neto (2000) define que três variáveis são determinantes para a sustentabilidade de uma rede: a diferenciação, a flexibilidade e a interdependência interfirmas. Tendo em vista que as redes ao serem idealizadas deverão ter objetivos voltados para a cooperação visando se tornar uma unidade organizacional em busca de unir forças para vencer as dificuldades e limitações, é imperativo que esse processo seja decorrente de uma diferenciação capaz de compreender e contemplar adequadamente as necessidades de gestão de pequenos negócios, tornando-os mais competitivos, lucrativos e sustentáveis.

\subsection{PESQUISAS REALIZADAS COM REDES INTEREMPRESARIAIS}

Ferreira et al. (2008) tiveram como objetivo mostrar que as redes organizacionais são viáveis, representando uma possibilidade e um caminho a ser seguido, tendo como foco de análise pequenas empresas do setor do varejo alimentar (supermercados). Para Ferreira et al. 
(2008) a constituição de redes de negócios tem representado um diferencial positivo para os pequenos supermercadistas, impactando diretamente em sua performance operacional, econômica e financeira.

Os autores realizaram uma pesquisa exploratória e qualitativa a partir de dados coletados junto a Associação Brasileira de Supermercados (ABRAS) no ano de 2005. Identificaram que o pequeno varejo supermercadista organizado em redes cresceu em 2004 em relação a 2003, $11,09 \%$ enquanto que o setor supermercadista cresceu apenas $2,57 \%$. Os autores atribuem esse crescimento ao profissionalismo do setor, ao reconhecimento do público corporativo e a aproximação do poder público. Os dados levantados pelos autores indicaram a eficiência das redes. Por exemplo, o faturamento médio anual por check out de $\mathrm{R} \$ 933,7$ mil dos pequenos organizados em rede contra uma média de $\mathrm{R} \$ 1,2$ milhões de faturamento por check out dos 300 maiores supermercados do país. Ao mesmo tempo, a produtividade também aumentou, sendo em 2003 a média de $98 \mathrm{~m}^{2}$ de loja por check out e em 2004 foi para $111 \mathrm{~m}^{2}$ de loja por check out.

Dados de 2004 ainda apontam que $70 \%$ das redes de pequenos supermercadistas têm menos de cinco anos de atividades, $60 \%$ têm mais de 20 associados e $40 \%$ das redes reúnem mais de 30 lojas cada. Faturaram em 2004 R\$ 12,02 bilhões participando com 12,3\% do faturamento total do segmento supermercadista. O número de lojas no Brasil totalizou 2.807 com 12.344 check outs, uma média de 4,4 check outs por loja.

Outra etapa da pesquisa realizada evidenciou três importantes pontos: 1) os motivos que levam os pequenos supermercados a se associarem a uma rede de negócios; 2) os objetivos da associação; e, 3) os ganhos obtidos. Entre os motivos se destacam a melhoria no poder de barganha junto aos fornecedores $(59,5 \%)$, a sobrevivência ante a concorrência $(29,7 \%)$, o acesso a um maior número de fornecedores $(5,4 \%)$, a operação com um mix mais qualificado e um melhor relacionamento com o cliente (ambos com 2,7\%). No item 2 os principais objetivos esperados com o ingresso em uma rede foram a compra de produtos mais baratos e o fortalecimento da união e da integração dos associados (ambos com 29,7\%), o crescimento e a sobrevivência no mercado $(24,3 \%)$, a negociação direta com a indústria $(10,8 \%)$ e a conquista de melhores prazos para pagamento $(5,4 \%)$.

Já o terceiro item avaliado, os ganhos obtidos por quem já participa de uma rede, foram as melhores condições de negociações com fornecedores $(43,2 \%)$, o aumento das vendas $(18,9 \%)$, a redução de custos $(5,4 \%)$ e o aumento da rentabilidade $(2,7 \%)$. Em resumo, os pontos 1, 2 e 3 acima levantados são vistos como vantagens para o ingresso em uma rede, por outro lado, as dificuldades encontradas na participação em redes, como as questões culturais $(70,3 \%)$, as burocracias legais $(64,9)$, a falta de cooperação e comprometimento entre os associados $(62,2 \%)$, a dificuldade de relacionamento com os grandes fornecedores $(59,5 \%)$ e a dificuldade para unificação e padronização do mix $(48,6 \%)$ são destacadas como desvantagens de ser associado.

A pesquisa revelou também como pontos positivos a uniformidade no treinamento operacional e gerencial, nos processos de recrutamento e seleção e na utilização de marcas próprias. Ferreira et al. (2008) concluíram que devido as dificuldades enfrentadas quando o pequeno varejista opera de forma isolada frente a busca pelo crescimento e a sustentabilidade, o associativismo tem crescido de forma organizada. As redes organizacionais surgem nesse novo contexto, por meio do cooperativismo, para obter novas fontes de vantagens competitivas necessárias no atual cenário marcado pela concorrência acirrada e alta competição.

Os autores concluem que no ambiente competitivo atual, as redes de cooperação são fundamentais para as organizações suprir suas deficiências, essas redes representam uma importante alternativa para as organizações conseguirem obter novos conhecimentos, recursos indispensáveis para a sustentabilidade e o crescimento do negócio. Os autores destacaram que em função da globalização e das modernas tecnologias de informação é de fundamental 
importância que os associados saibam desenvolver competências e habilidades para permanecer vinculados a uma rede e saber explorá-la em favor da própria competitividade (FERREIRA et al., 2008).

Boehe e Silva (2003) analisaram sete características de uma rede de padarias e confeitarias em Novo Hamburgo/RS, a fim de observar problemas e perceber desafios comuns às alianças estratégicas que permitam a expansão da rede no setor industrial. Argumentam que há um contraste entre a alta relevância das pequenas empresas como geradoras de empregos de um lado e o peso relativamente baixo como geradoras de riquezas, com barreiras para uma articulação econômica maior, traduzidas em acesso limitado a fontes de financiamento, o fato de depender de grandes fornecedores que ditam os preços unilateralmente e ainda o baixo nível de inovação e capacitação tecnológica, sendo que a origem dessas barreiras repousa na falta de massa crítica em termos de demanda, escala de produção e poder financeiro (BOEHE; SILVA, 2003). Dessa forma foi realizado um estudo visando articular a realidade de dificuldades levantadas com as características que possibilitem a expansão e consolidação de redes visando sustentabilidade de seus membros. Viabilizaram a pesquisa por meio de um estudo de caso com a referida rede com aplicação de entrevistas e análise documental para triangulação dos resultados. As características estudadas são apresentadas na Figura 1:

Figura 1: Características exploradas e suas conexões

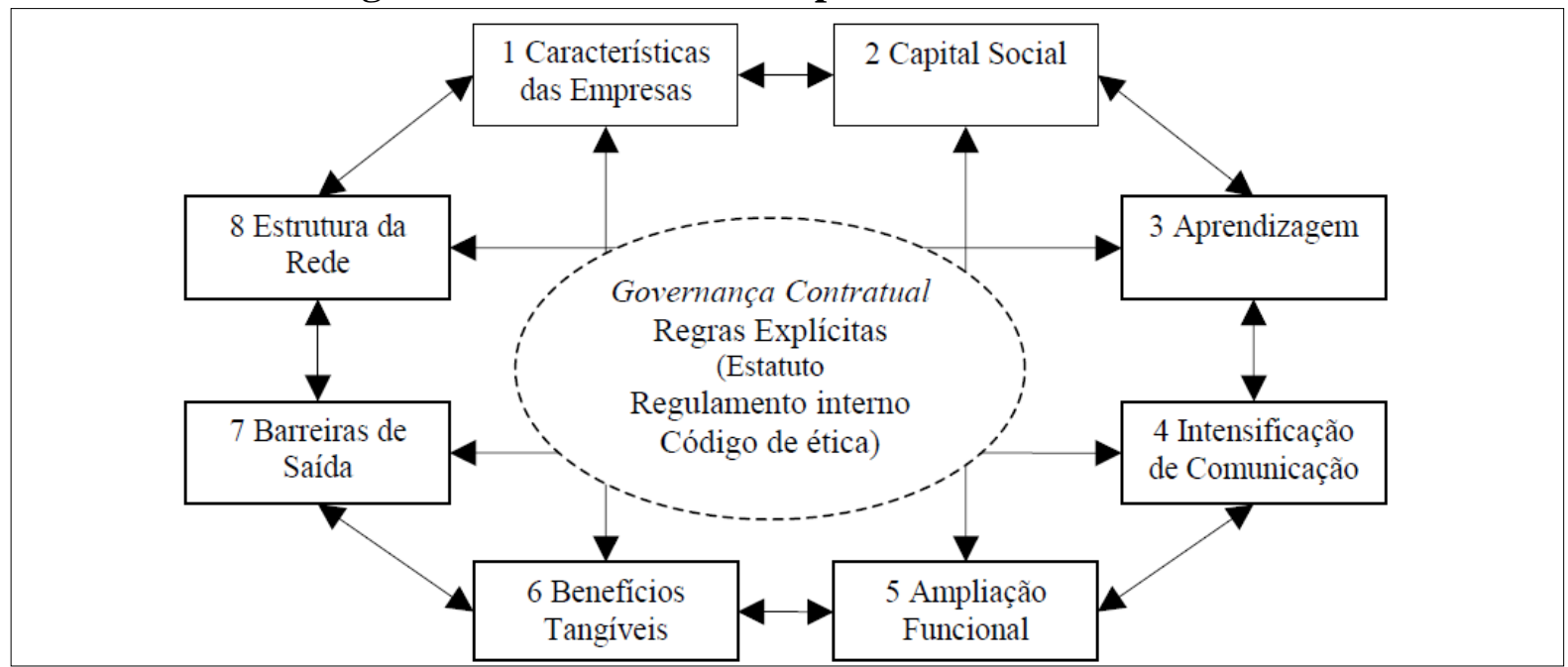

Fonte: Boehe e da Silva (2003)

Encontraram como resultado da pesquisa que a estrutura da rede pode afetar a troca de informação, e a rede analisada apresenta membros que se identificam mutuamente e dessa forma estão provavelmente mais dispostos a trocar recursos intangíveis. Outra observação refere-se a falta de oportunidades para aprendizagem dentro da rede, decorrentes da falta de capital social (confiança interpessoal, reciprocidade, expectativas e normas compartilhadas), ou do fato da rede ser homogênea demais em relação ao seu conhecimento técnico ou pouca profundidade funcional (relacionado as atividades da cadeia de valor nas quais cooperam as empresas que participam da rede). Os autores sugerem um plano estratégico para que seja possível gerar um efeito sustentável para a rede (BOEHE; SILVA, 2003).

Concluem argumentando que uma vez superada a questão da massa crítica se daria origem a uma dinâmica de crescimento. E que uma vez aceita a ideia de que o associativismo gera benefícios para todos cria-se uma base para uma economia que pode crescer inclusive na presença de situações macroeconômicas desfavoráveis ou na onipresença de oligopólios cujo poder de mercado tem sufocado as pequenas empresas (BOEHE; SILVA, 2003).

Balestro et al. (2004) examinaram o papel de uma rede voltada à cadeia de suprimento da indústria do petróleo e gás no que tange o desenvolvimento de competências e capacidades

GєCont, v. 4, n. 1, Floriano-PI, Jan-Jun. 2017. 
dinâmicas das empresas participantes. Para esses autores, no ambiente competitivo em que a inovação se torna a principal fonte de vantagem competitiva, o desenvolvimento da capacidade tecnológica das empresas exige uma quantidade de recursos cada vez maior, o que faz com que o tema da cooperação interempresarial se torne parte do cotidiano das empresas, sejam elas grandes ou pequenas. Nesse artigo Balestro et al. (2004) utilizaram um conceito de rede abrangente, incluindo outros atores, como universidades, centros tecnológicos, instituições financeiras e Governo do Estado. A Figura 2 esclarece os relacionamentos entre os membros da rede.

Figura 2: Atores da Rede PETRO-RS e seus vínculos

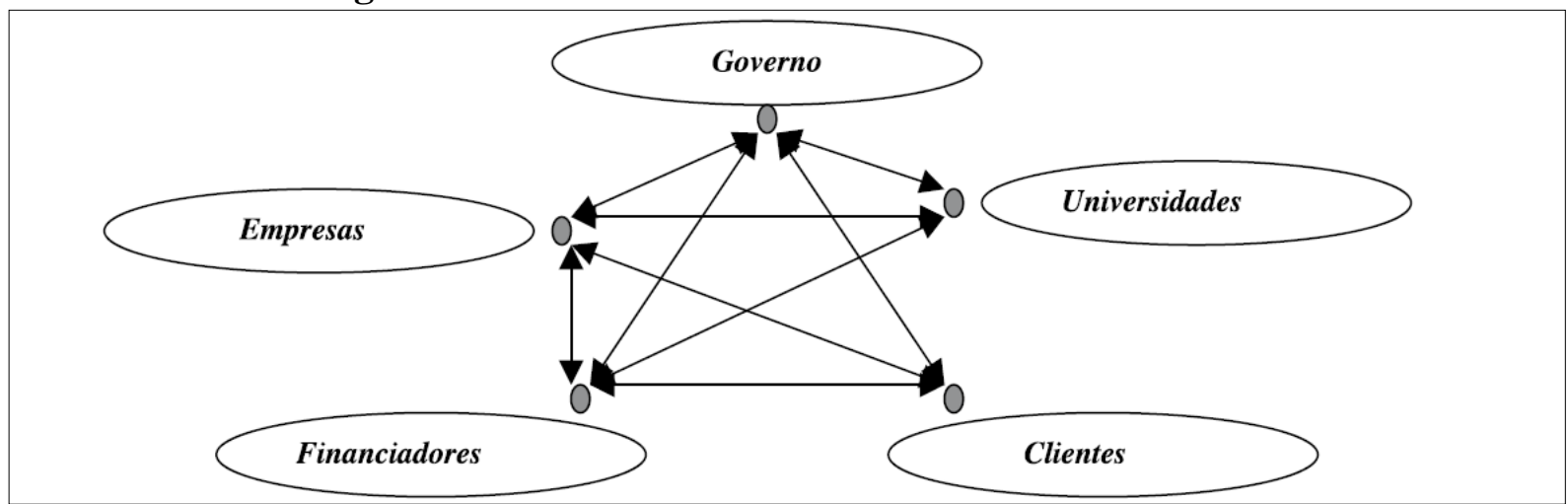

Fonte: Balestro et al. (2004)

Para realização da análise empírica foi procedido ao estudo de caso por meio da utilização de coleta e análise de dados primários (entrevistas semiestruturadas com os coordenadores da Secretaria Executiva da rede no período de 1999 a 2002). Como resultado pode-se dizer que a Rede PETRO-RS possibilitou o desenvolvimento de competências para as empresas que a integram. Para os autores a Petrobrás, pela sua posição, demanda que seus fornecedores tenham competências e capacidade tecnológica condizente com a realidade da concorrência, possibilitando condições para a inserção das empresas da Rede PETRO-RS no mercado global de fornecedores da indústria de petróleo e gás. Ao estreitar as relações com a Petrobrás essas empresas passam a ter acesso a informações qualificadas, que contribuem para o seu processo de adaptação e reconfiguração de habilidades organizacionais necessárias para a obtenção de uma vantagem competitiva sustentada na cadeia de suprimentos.

Outro aspecto importante observado pelos autores foi o potencial de mercado revelado pelas atividades de promoção comercial realizada pela rede, na qual muitas empresas passaram a redefinir suas estratégias. Em resumo, as capacidades dinâmicas identificadas pelos autores (BALESTRO et al., 2004) foram os processos organizacionais, a capacidade de comercialização e suas próprias trajetórias. Os autores concluíram que mesmo com importantes avanços proporcionados pela rede, a cooperação mútua ainda pode proporcionar melhorias e que a coordenação da rede precisa ser mais consolidada junto aos demais atores para reduzir sua dependência em relação às mudanças do Governo. Também é necessário que ela desenvolva mecanismos que possibilitem maior interconectividade dos seus membros, fortalecendo o imbricamento e facilitando o desenvolvimento de relações de confiança entre os diversos atores envolvidos (BALESTRO et al.,2004).

\section{$2.8 \quad$ REDES DE SUPERMERCADOS}

Segundo Barbosa, Almeida e Villela (2008) a história das redes de pequenos supermercados inicia com a abertura do mercado brasileiro em 1990 e a estabilização econômica em 1995 com a implantação do Plano Real, as quais favoreceram a expansão das 
redes de supermercados nacionais e a implantação de grandes redes supermercadistas mundiais no Brasil. Essa nova dinâmica fez com que os pequenos varejistas supermercadistas se defrontassem com uma nova situação de competitividade e buscassem estratégias e recursos para garantir sua permanência no mercado. Como solução, os pequenos supermercados passaram a associar-se em redes, inicialmente para formar centrais de compra, com o objetivo de reduzir custos na aquisição de mercadorias e poder diminuir o preço de venda aos consumidores finais (WILDER, 2003).

Barbosa, Almeida e Villela (2008) argumentam que inicialmente as redes foram formatadas como uma central de compras, mas ao longo do tempo as redes foram evoluindo, criando centrais de recebimento e distribuição de mercadorias, além de procedimentos comuns relacionados às áreas de publicidade e finanças e integração tecnológica, culminando com a contratação de executivos de mercado para gerir a rede de forma neutra.

Assim, Ferreira et al. (2008) argumenta que as centrais de compras nos últimos anos ganharam força e destaque passando a ser vistas com mais atenção pelo mercado. São organizações com características próprias, que a cada dia ampliam sua área de atuação na gestão dos negócios de seus associados. De acordo com Barbosa, Almeida e Villela (2008) em 2000 o Brasil possuía 60 centrais de compras de pequenos supermercadistas e aproximadamente 150 lojas associadas, em 2005 o número subiu para 150 centrais com aproximadamente 3.050 lojas, tendo sido reduzido para 130 redes em 2009 com 3.540 lojas associadas (MELO, 2010). De acordo com estatísticas atualizadas da ABRAS (2012) Minas Gerais tem 11 redes de pequenos supermercados, entre as 30 maiores redes do Brasil.

\section{METODOLOGIA DA PESQUISA}

\subsection{CLASSIFICAÇÃO DA PESQUISA}

Esta pesquisa é classificada conforme a tipologia proposta por Beuren et al. (2008): quanto aos objetivos, quanto aos procedimentos e quanto à abordagem do problema. Assim, quanto aos objetivos esta pesquisa é exploratória. Farias Filho e Arruda Filho (2013) destacam que a pesquisa exploratória visa desenvolver maior familiaridade com o tema, concedendo uma visão geral acerca do fato. Portanto, esse tipo de pesquisa é realizado, sobretudo, quando o tema escolhido é pouco explorado.

Com relação aos procedimentos de pesquisa, estes se referem à forma pela qual se conduz o estudo, com um foco na maneira como se obtém os dados (BEUREN et al., 2008). Foi utilizada nessa pesquisa primeiramente a pesquisa bibliográfica seguida de entrevistas com funcionários administrativos da Associação Mineira de Supermercados (AMIS) e gestores das redes de empresas supermercadistas da região metropolitana de Belo Horizonte. Finalizando as tipologias propostas por Beuren et al. (2008), a presente pesquisa se caracteriza quanto à abordagem do problema como um estudo qualitativo, uma vez que possibilitou um estudo mais aprofundado das relações intra e inter-redes. Segundo Beuren et al. (2008, p. 92) "[...] na pesquisa qualitativa concebem-se análises mais profundas em relação ao fenômeno que está sendo estudado", neste caso as redes organizacionais formadas pelos pequenos supermercadistas da região metropolitana de Belo Horizonte.

\subsection{POPULAÇÃO E AMOSTRA}

A população de estudo é composta pelas sete redes do varejo supermercadista com sede na região metropolitana de Belo Horizonte, conforme dados extraídos da AMIS em 30/03/2013, complementados por informações fornecidas pelos próprios gerentes das redes entrevistadas. 


\subsection{INSTRUMENTO DE COLETA DE DADOS}

Dois são os instrumentos de pesquisa. O primeiro é a entrevista com base em um roteiro semiestruturado pelos autores e o segundo é o questionário. Sendo a entrevista o principal procedimento desta pesquisa, exigir-se-á rigor e organização para a realização do estudo. Nesse sentido define-se um protocolo de pesquisa, podendo este ser definido como "[...] um instrumento orientador e regulador da condução da estratégia de pesquisa" (MARTINS; THEÓPHILO, 2009, p.66).

A pesquisa de campo com entrevista do tipo semiestruturada foi realizada em dois momentos, o primeiro com pesquisa feita na AMIS para levantar aspectos gerais sobre as redes da região metropolitana de Belo Horizonte, contendo os seguintes questionamentos: Quantas redes são na Grande BH? Como as redes se organizam, são setoriais (multissetoriais)? Horizontais? Formais? Quem faz parte de cada rede? Quantidade de lojas e se possível nome das lojas participantes.

O segundo momento, contemplando a entrevista com gestores das redes foi dividido em duas partes, sendo que na primeira parte foi estruturada uma entrevista que apresenta questões abertas e também questões com respostas do tipo sim ou não. Essas questões procuraram explorar a forma de atuação e interação, procurou saber sobre a sua estrutura física, se a rede possui central de compras, se possui central de recebimento e distribuição de mercadorias, assim como se há procedimentos relacionados à publicidade, finanças, integração tecnológica e de treinamento de empregados. Também procurou saber se há interação entre as redes, quais são as políticas de negociação e como é sua estrutura de gestão. Ainda procurou saber se as redes são geridas por executivos de mercado, quantos colaboradores e em quais posições atuam. Qual o organograma, e conselhos: fiscal, de administração, deliberativo ou outros. Ainda perguntou se havia reuniões periódicas e de quanto em quanto tempo eram realizadas.

Na segunda parte da entrevista com os gestores, foi aplicado um questionário que utiliza a escala de Likert, contendo doze afirmações sobre vantagens percebidas e seis afirmações sobre as desvantagens percebidas de ser um associado de rede, compreendendo uma escala que varia de 01 (discordo totalmente), 02 (discordo parcialmente), 03 (nem discordo nem concordo), 04 (concordo parcialmente) e 05 (concordo totalmente), em cada quesito avaliado.

\section{ANÁLISE DOS DADOS}

De acordo com dados obtidos na AMIS em março de 2013, relativos ao último levantamento realizado (AMIS, 2010), são 39 centrais de negócios cadastradas na AMIS no estado de Minas Gerais. Dessas 39 redes, sete possuem sede na região metropolitana de Belo Horizonte, sendo elas: Rede Arrastão, Rede Fácil, Rede Gerais, Rede Mania, Rede Super Varejista, Rede Valor e Rede Paranaíba. A Figura 3 apresenta a localização das redes no estado de Minas Gerais. 
Figura 3: Centrais de negócios no estado de Minas Gerais

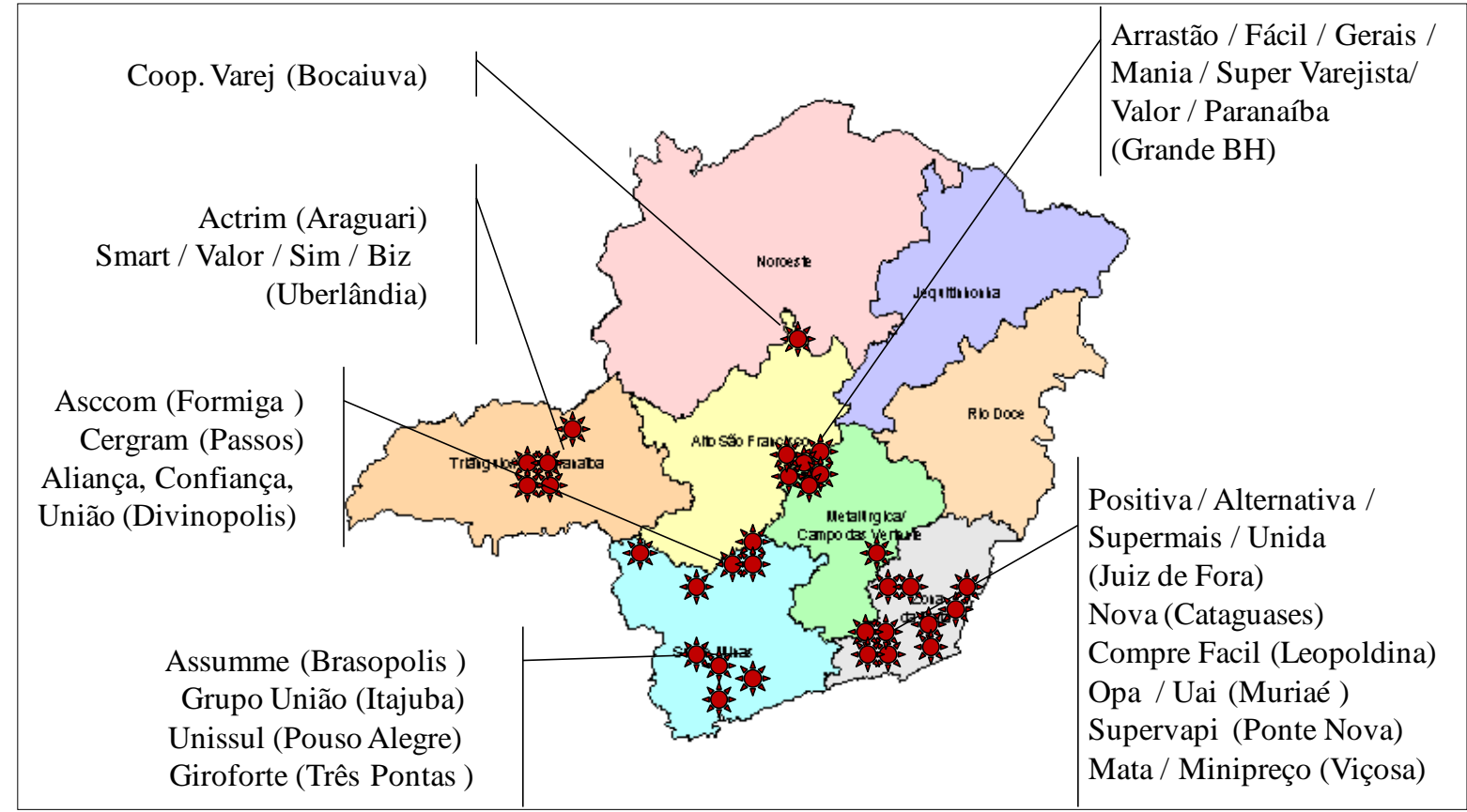

Fonte: Adaptado de AMIS (2010)

Pela figura observa-se que há maior concentração de redes nas regiões sul e sudeste do estado, enquanto na região norte apenas uma rede possui sede, já na região do triangulo são cinco redes, dessa forma na região metropolitana de Belo Horizonte, concentram-se $18 \%$ das centrais negócios do estado. Ainda de acordo com dados da AMIS (2010) o faturamento anual das centrais situadas em Minas Gerais no ano de 2009 foi aproximadamente R $\$ 10,8$ bilhões, sendo o faturamento médio por loja de $\mathrm{R} \$ 385.856$, o faturamento médio por check out de $\mathrm{R} \$ 85.686$, o faturamento médio por $\mathrm{m}^{2}$ de $\mathrm{R} \$ 9.917$ e o faturamento médio por empregado de $\mathrm{R} \$ 17.978$, valores muito próximos dos valores descritos por Ferreira et al. (2008) em relação aos dados nacionais.

\subsection{ANÁLISE DAS FORMAS DE ATUAÇÃO E INTERAÇÃO INTRA E INTERREDES}

Considerando as sete redes da região metropolitana de Belo Horizonte, todas são horizontais, setoriais do ramo varejista supermercadista, sendo que quatro são formalizadas e possuem CNPJ e três não são formalizadas. Juntas, somam 162 supermercados participantes, sendo a menor das redes com cinco lojas e a maior com 37 lojas. O Gráfico 1 apresenta o percentual de lojas participantes por rede. 


\section{Gráfico 1: Distribuição das lojas de acordo com as redes da região metropolitana de Belo Horizonte}

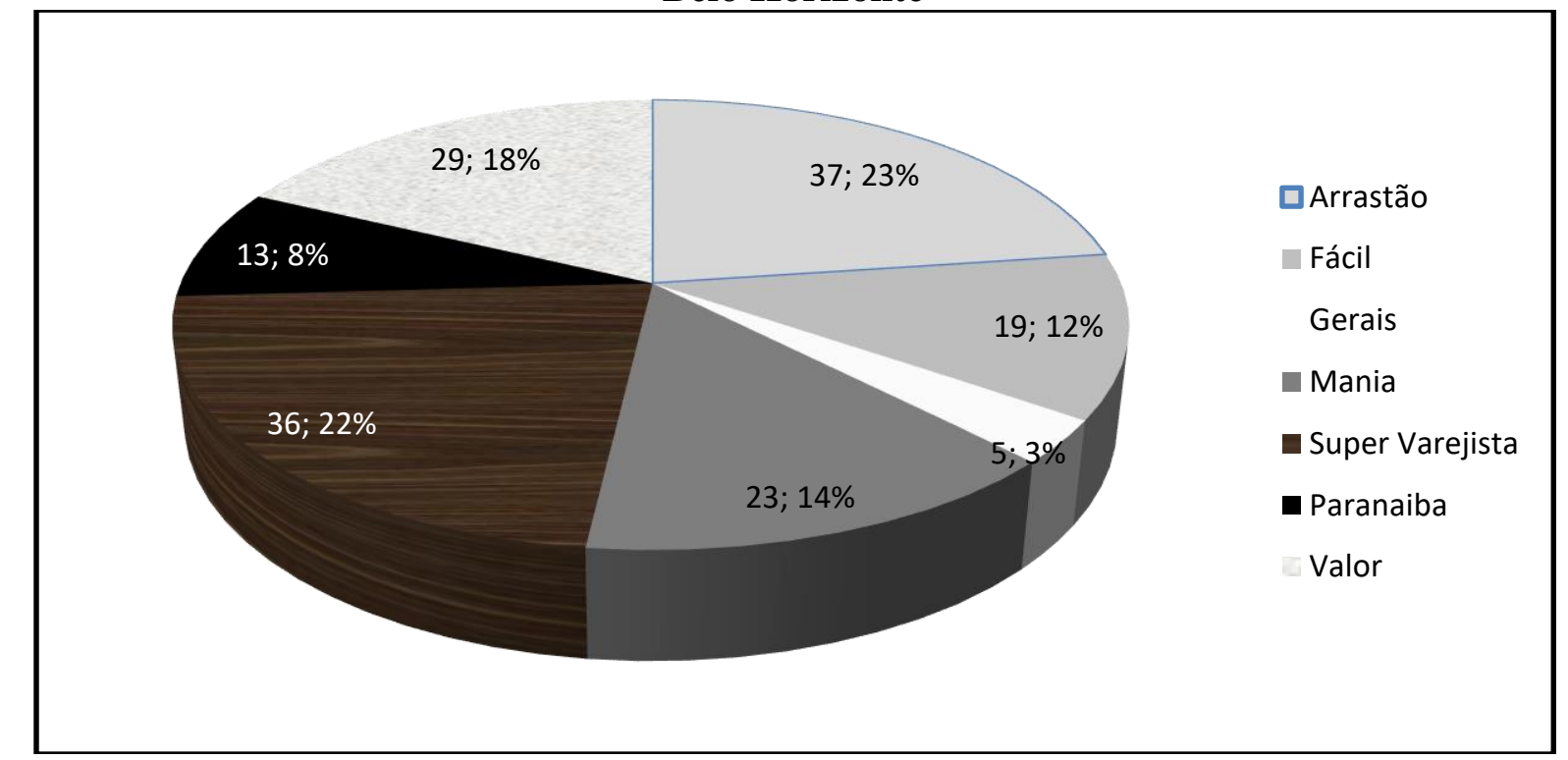

Fonte: Dados da Pesquisa

As redes não possuem atividades entre si (interredes), somente possuem atividades em relação aos próprios associados (intrarrede). Nesse aspecto destaca-se a atividade de compras coletivas para os associados, por meio de centrais de compras. Em relação a central de compras todas as redes possuem, sendo que quatro delas possuem também centro de distribuição. Duas das redes que possuem centro de distribuição possuem parceiros logísticos que fazem a distribuição dos produtos comprados pela rede para a central e da central distribui para os associados. No entanto os associados de duas redes precisam buscar as mercadorias na central.

Ainda neste aspecto de compras e distribuição, outro procedimento utilizado pelas redes é a negociação direta com os fornecedores para estes entregarem loja a loja, principalmente produtos com maior volume e maior giro, tais como produtos da cesta básica, cerveja, papel higiênico, milho verde, dentre outros produtos de baixo valor agregado e com um volume de vendas alto.

Um segundo aspecto diz respeito à interação entre os associados da rede e a forma de comunicação. Somente uma rede usa programa próprio pelo site para solicitação de pedidos e para comunicação interna, enquanto outra usa um servidor na administração, onde é feito a precificação e a entrada das mercadorias. Quatro redes possuem comunicação por meio de programas como messager e skype, e as demais redes se comunicam por telefone e e-mails. Ainda no quesito comunicação destaca-se o apoio à eficiência tecnológica, onde a rede promove a interação dos associados a fim de trocarem informações sobre novas possibilidades de investimentos em novas tecnologias, como sistemas integrados do tipo ERP.

Um terceiro aspecto diz respeito a procedimentos comuns relacionados à área de publicidade. Todas as redes pesquisadas fazem reuniões para definir quais produtos colocar em seus tabloides de ofertas. Uma das redes faz três tabloides de ofertas por mês, três redes fazem duas vezes por mês e as outras três redes fazem um tabloide de oferta por mês. Essa forma de interação garante que os preços praticados pelas lojas da rede sejam os mesmos para os produtos ofertados.

Como outras formas de publicidade, destaca-se que três redes fazem divulgação em rádio e nos uniformes dos empregados, enquanto que duas redes divulgam sua marca por meio de carro de som, uma rede divulga pela TV. Uma das redes usa uma forma de publicidade com o nome de guerrilha, terça saudável, quarta do pão, quinta da carne e sexta maluca. Nestes dias 
todas as lojas da rede fazem ofertas em busca de fidelizar os clientes e trazê-los na loja durante o máximo de dias da semana.

O quarto aspecto tratado é a forma de interação quanto à área financeira. Quatro redes compram em CNPJ próprio e redistribui para os associados os quais efetuam o pagamento para a rede, e esta por sua vez efetua o pagamento aos fornecedores, sendo que uma delas cobra um percentual sobre o preço de compra para manutenção da rede. Cinco redes cobram uma taxa mensal dos associados para manutenção dos custos fixos do escritório, do galpão e dos salários dos funcionários da rede, enquanto que outras duas não cobram taxas e nem percentual sobre os produtos comprados. Uma dessas redes que tem como sede a estrutura de um supermercado usa as bonificações dos fornecedores para custear as despesas.

O último aspecto tratado neste tópico é quanto à gestão de recursos humanos realizada pelas redes para seus associados. Nesse sentido, cinco redes não oferecem nenhum serviço na área de RH para seus associados, enquanto outras duas redes disponibilizam para os associados treinamentos para os empregados e também para os proprietários dos supermercados e uma das redes disponibiliza treinamentos apenas para os proprietários.

\subsection{IDENTIFICAÇÃO DA FORMA DE NEGOCIAÇÃO DAS REDES}

As redes compram com prazos que variam entre 21 e 35 dias, sendo que cinco redes afirmarem ter um prazo médio de 28 dias. Em relação a obtenção de descontos, o menor desconto percebido por uma rede foi de $2 \%$, enquanto que o maior desconto percebido foi de $6 \%$, as cinco outras redes percebem um desconto médio de 5\%. Essas compras são faturadas para a central da rede ou direto para as lojas.

\subsection{ANÁLISE DAS VANTAGENS E DESVANTAGENS DE SER UM ASSOCIADO}

De acordo com as redes entrevistadas, entre as 12 vantagens competitivas identificadas na literatura as quatro maiores vantagens competitivas percebidas pelos gestores entrevistados foram: 1) aproveitar competências e utilizar know how das outras empresas associadas (a maior vantagem competitiva percebida pelos gestores das redes); 2) aumentar o poder de compra e a melhoria no poder de barganha junto aos fornecedores; 3) acesso a um maior número de fornecedores e 4) aumento das vendas.

Por outro lado os supermercadistas mineiros organizados em rede não percebem como uma grande vantagem competitiva a sobrevivência frente ao mercado e a possibilidade de conquistar maiores prazos para pagamento. O Quadro 2 se dedica a apresentar o quadro completo de vantagens competitivas extraídas da literatura e a pontuação média obtida por meio da escala de Likert.

$\mathrm{Na}$ outra ponta da análise foi solicitado aos entrevistados que pontuassem as desvantagens de participar de uma rede, conforme obtidas na revisão de literatura. Nesse sentido a maior desvantagem percebida foi a diferença entre o tamanho das lojas, seguida das diferenças culturais entre os membros e da dificuldade para unificação e padronização do mix. 
Quadro 2: Vantagens percebidas de ser associado a redes

\begin{tabular}{|c|l|c|}
\hline Item & \multicolumn{1}{|c|}{ Descrição } & $\begin{array}{c}\text { Pontuação } \\
\text { Média }\end{array}$ \\
\hline 1 & Aproveitar competências e utilizar know how das outras empresas & 5,00 \\
\hline 2 & Aumentar o poder de compra e melhoria no poder de barganha junto aos fornecedores & 4,86 \\
\hline 3 & Acesso a um maior número de fornecedores & 4,86 \\
\hline 4 & Aumento das vendas & 4,43 \\
\hline 5 & $\begin{array}{l}\text { Exercer uma pressão maior no mercado, aumentando a força competitiva, possibilitando } \\
\text { benefícios ao cliente. }\end{array}$ & 4,29 \\
\hline 6 & Fortalecimento da união e da integração dos associados & 4,29 \\
\hline 7 & Redução de custos & 4,00 \\
\hline 8 & Aumento da rentabilidade & 4,00 \\
\hline 9 & Dividir riscos e custos de explorar novas oportunidades & 3,86 \\
\hline 10 & A operação com um mix mais qualificado e um melhor relacionamento com os clientes & 3,86 \\
\hline 11 & Crescimento e a sobrevivência no mercado & 3,86 \\
\hline 12 & Conquista de melhores prazos para pagamento & 3,86 \\
\hline
\end{tabular}

Fonte: Dados da Pesquisa

Ainda nesse contexto, a realização das entrevistas possibilitou observar que há diferenças educacionais entre os associados, mas existe cooperação e comprometimento entre eles. Não foi percebido excesso de burocracias legais interna na rede. Por fim, pode-se perceber ainda diante das entrevistas que as burocracias existentes são necessárias para que haja controle sobre os processos de gestão e também sobre os associados para que eles sigam as normas préestabelecidas. O Quadro 3 apresenta o resultado da pontuação das desvantagens percebidas.

\section{Quadro 3: Desvantagens percebidas de ser associado a redes}

\begin{tabular}{|c|l|c|}
\hline Item & \multicolumn{1}{|c|}{ Descrição } & $\begin{array}{c}\text { Pontuação } \\
\text { Média }\end{array}$ \\
\hline 1 & Diferenças entre o tamanho das lojas participantes & 4,86 \\
\hline 2 & Diferenças culturais entre os membros & 4,71 \\
\hline 3 & Dificuldade para unificação e padronização do mix & 4,71 \\
\hline 4 & Diferenças educacionais entre os membros & 4,29 \\
\hline 5 & Falta de cooperação e comprometimento entre os associados & 3,57 \\
\hline 6 & Excesso de burocracias legais interna na rede & 2,86 \\
\hline
\end{tabular}

Fonte: Dados da Pesquisa

Por fim, por meio das entrevistas foi percebido que o pequeno varejo supermercadista da região metropolitana de Belo Horizonte tem procurado se organizar em redes para juntos terem maior poder de negociação e com isso terem melhores preços, assim poderão competir com as grandes redes mantendo a lucratividade esperada.

\subsection{ANÁLISE DAS SIMILARIDADES E DIFERENÇAS ENTRE AS ESTRUTURAS DE GESTÃO DAS REDES}

Três redes possuem um organograma formal composto por um presidente, diretores, assistentes administrativos, secretária e compradores, enquanto que as outras três também dizem ter um organograma, mas informal. Uma rede é administrada por um atacado que contém conselho fiscal, administrativo e deliberativo, enquanto quatro redes possuem conselho 
formado pelos associados, com função de votar assuntos ordinários de interesse comum e apenas uma não tem nenhum tipo de conselho. Das sete redes, duas tem executivos de mercado, as demais são geridas por proprietários de supermercados da rede.

Todos os supermercados associados às redes são monitorados com relação aos pagamentos a fornecedores, caso tenham boletos em atraso, é feito um alerta para que o pagamento seja feito imediato, caso persista o atraso o associado pode até ser excluídos da rede.

Duas redes são fechadas e não aceitam novos associados, enquanto que outras cinco redes para admitir novos associados fazem uma pesquisa sobre a situação financeira do supermercado e uma reunião com os demais sócios para definir sobre a entrada ou não do supermercado, respeitando sempre as regras previamente definidas pela rede.

\section{CONSIDERAÇÕES FINAIS}

Considerando o objetivo proposto para esse trabalho que foi identificar como o pequeno varejo supermercadista da região metropolitana de Belo Horizonte se organiza em redes, ou seja, analisar as formas de atuação e interação intra e inter-redes; identificar a forma de negociação das redes e as vantagens e desvantagens de ser um associado e destacar as similaridades e diferenças entre as estruturas de gestão utilizadas pelas redes, entende-se que o mesmo foi atingido tendo como principais pontos que podem ser destacados que o pequeno varejo supermercadista da região metropolitana de Belo Horizonte tem procurado se organizar em redes para juntos terem maior poder de negociação e com isso terem melhores preços, assim poderão competir com as grandes redes mantendo a lucratividade esperada. Em rede conseguese estar mais próximo aos fornecedores, aumentando as possibilidades de poder manter um mix melhor e sem ruptura. Todas as redes possuem central de compras, três possuem centro de distribuição. O prazo médio de compra das redes é de 28 dias e os descontos médios percebidos por estarem em redes é de $5 \%$.

Aproveitar competências e utilizar know how das outras empresas associadas é a maior vantagem percebida pelos associados, embora melhorar o poder de barganha aumentando o poder de compra e com isso melhorar o lucro e as vendas também foram vantagens percebidas pelos associados, enquanto que a afirmação de que a participação em redes garante a sobrevivência ante a concorrência não foi entendida como verdade. Para os entrevistados a rede é uma forma de os associados buscarem minimizar os custos dos produtos. Embora as redes pesquisadas não interajam entre si, estão todas associadas à AMIS.

Como limitação da pesquisa destaca-se que foi utilizada a base de dados da AMIS não considerando eventuais redes não associadas e o fato de terem sido entrevistados apenas redes situadas na região metropolitana, portanto, seus resultados não puderam ser extrapolados por se tratar de uma amostra regionalizada, e de certa forma, observa-se também o não emprego de validação de construtos, o que poderia ser adotado para novos estudos. Portanto, como sugestões para trabalhos futuros, se propõe ampliar a base de dados para outras regiões do país, e realizar uma análise comparativa com outras realidades do Brasil e outros países, possibilitando assim, verificar variações ou evidências conforme constatadas no presente estudo.

Conclui-se que as redes estão se profissionalizando, e entre as sete redes pesquisadas muitas foram as diferenças encontradas em todos os quesitos, seja na forma de interação com seus associados, seja na forma de negociação ou mesmo na estrutura física e na estrutura de gestão.

GeCont, v. 4, n. 1, Floriano-PI, Jan-Jun. 2017. 


\section{REFERÊNCIAS}

ABRAS - Associação Brasileira de Supermercados. Estatística das Redes de Pequenos Supermercados Brasileiros. Disponível em: http://www.abrasnet.com.br/, acesso em 20/02/2013.

AMATO NETO, João. Organizador. Redes Entre Organizações: Domínio do Conhecimento e da Eficácia Operacional. São Paulo: Atlas, 2005.

AMATO NETO, João. Redes de Cooperação Produtiva e Clusters Regionais. São Paulo: Atlas, 2000.

ANTHONY, Robert; GOVINDARAJAN, Vijay. Sistemas de Controle Gerencial. São Paulo: Atlas, 2008.

BALESTRO, Moisés Villamil; ANTUNES JÚNIOR, José Antônio Valle; LOPES, Marcelo Carvalho; PELLEGRIN, Ivan de. A Experiência da Rede Petro - RS: Uma Estratégia Para o Desenvolvimento das Capacidades Dinâmicas. Revista de Administração Conteporânea. v.8. São Paulo: 2004.

BARBOSA, Jose Geraldo Pereira, ALMEIDA, Jozias Castro de, VILLELA, Lamounier Erthal. Redes de Pequenos e Médios Supermercados: um Estudo Exploratório dos Fatores Determinantes de Competitividade. XI SEMEAD, SP, 2008.

BEUREN, Ilse Maria (Organizadora). Como Elaborar Trabalhos Monográficos em Contabilidade. São Paulo: Atlas, 2008.

BOEHE, Dirk; DA SILVA, Karen Menger. Rumo a uma estratégia de desenvolvimento de redes de PME's. In: XXVII Encontro da Anpad. 2003, Atibaia-SP. Anais... Atibaia-SP, 2003.

CASSAROTO FILHO, N.; PIRES, L. H. Redes de pequenas e médias empresas e desenvolvimento local: Estratégias para a Conquista da Competitividade Global com Base na Experiência Italiana. São Paulo: Atlas, 2001.

CASTELLS, M. A sociedade em rede. Rio de Janeiro: Ed. Paz e Terra, 2000.

FARIAS FILHO, Milton Cordeiro; ARRUDA FILHO, Emilio J. M. Planejamento da pesquisa científica. São Paulo: Atlas, 2013.

FERREIRA, Roberto do Nascimento; SANTOS, Antônio Carlos dos; NAZARETH, Luiz Gustavo Camarano; BERNARDO, Denise carneiro dos reis; GIAROLA, Eduardo. Redes Organizacionais no Varejo Alimentar. In: XXXII Encontro da Anpad. 2008, Rio de JaneiroRJ. Anais... Rio de Janeiro-RJ, 2008.

LENZI, Fernando; KIESEL, Marcio (Organizadores). O Empreendedor de Visão. São Paulo: Atlas, 2009.

LIMA FILHO, Dario de Oliveir; MAIA, Fabrício Simplício; SPROESSER, Renato Luiz; MORAIS, Fabio; MORAIS, Roberta. Redes de Cooperação no Varejo Alimentar de 
Vizinhança: Percepções dos Associados. Revista Gestão e Produção. v.13, n.2, p.311-324, mai.-ago. 2006.

MARTINS, Gilberto A.; THEÓPHILO, Carlos R. Metodologia da investigação científica para ciências sociais aplicadas. São Paulo: Atlas, 2009.

MELO, Natália Máximo e. Centrais de Negócios de Pequenas Empresas do setor Supermercadista: Entre a Concorrência e a Cooperação. Revista Intratextos, Rio de Janeiro. vol.2, n 1 , pp. $76-96,2010$.

WILDER, Ariel. Mudanças no setor supermercadista e a formação de associações de pequenos supermercados. Dissertação de Mestrado. Escola Superior de Agricultura Luiz de Queiroz. Piracicaba - SP, 2003.

* Agradecimento à FAPEMIG pelo apoio no desenvolvimento do estudo.

GєCont, v. 4, n. 1, Floriano-PI, Jan-Jun. 2017. 